\title{
Day Case Strabismus Surgery Without Post-Operative Ocular Medication. A Masked Randomised Study
}

\author{
M. C. HAGAN and W. J. DINNING \\ London
}

\begin{abstract}
Summary
A masked, randomised study was designed to test the hypothesis that day case strabismus surgery and the absence of post-operative topical medication is a plan of management that does not compare unfavourably with discharge from hospital on the day after surgery with topical antibiotic and anti-inflammatory therapy for 14 days. The results indicate that patients who have day case surgery do not have more complications than overnight stay patients and that their inflammation and discomfort settle just as quickly without topical therapy. Medical, social and financial benefits of day case surgery are noted.
\end{abstract}

Day case surgery is becoming accepted practice for many common procedures, including strabismus surgery. ${ }^{1}$ Strabismus has been identified as a condition for which day case surgery may become the norm. ${ }^{2}$ There is much to be said for minimising the length of time children are removed from familiar surroundings.

There are no grounds for expecting early discharge from hospital to have a detrimental effect on the local results of surgery. Most objections relate to concern about adequate recovery from general anaesthesia. These can be met by operating in the morning so as to allow the afternoon for recovery.

The use of post-operative topical medication is widespread in the form of antibiotic drops or ointment, commonly combined with anti-inflammatory agents. The value of postoperative antibiotics has been seriously questioned. Kirkby, Clayden and Harcourt (unpublished) observed in 188 patients given no postoperative antibiotics only one case of culture-positive conjunctivitis. This responded rapidly to treatment with chloramphenicol drops. It has been our practice to instil oxyphenbutazone/chloramphenicol ointment twice daily for 14 days.

To answer the following questions:

(1) is day case strabismus surgery safe?

(2) is our customary prophylactic post-operative medication necessary?

we compared the findings in one group of patients treated 'conventionally' (overnight stay in hospital and 14 days topical antibiotic/ anti-inflammatory ointment) with those in a 'study' group treated as day cases and given no per- or post-operative medication.

\section{Materials and Methods}

By computer, a list of consecutive numbers was generated to each of which overnight stay or day case, and one or other surgeon had been allotted at random. Healthy patients aged between 11 months and 6 years requiring strabismus surgery were assigned successive numbers on this list at the time the decision was made to operate. The study was then discussed with the parents and informed consent obtained. If consent was not given the allotted

From: West Middlesex Ealing and Ashford Hospitals.

Correspondence to: W. J. Dinning, The Ealing Hospital, Uxbridge Road, Southall, Middlesex.

Presented at the Annual Meeting of The Ophthalmological Society of the United Kingdom, April, 1987. 


\section{PARENTAL QUESTIONNAIRE}

(1) temperature .............. normal raised (subjectively)

(2) cough

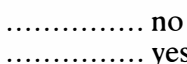

(3) vomiting

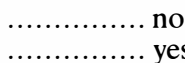

(4) sleep

(5) appetite

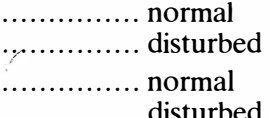

(6) apparent eye discomfort (as suggested by attempts at rubbing)

...... none $=0$

...... slight $=1$

..... moderate $=2$ ...... severe $=3$

Fig. 1. Parental questionnaire

number was designated a failure. After consent parents were told which group their child was in.

The sample size was chosen to give the study a power of 90 per cent of detecting a difference of 1 or greater in mean redness scores between the two groups (see post-operative assessment). This indicated 21 or more patients in each group. Fifty patients were randomised as described. There were 8 failures for various reasons (see results). Of the remaining 42, 22 were randomised to the 'conventional' group and 20 to the 'study' group.

Patients were admitted at $8 \mathrm{a} . \mathrm{m}$. fasting for an operating list beginning at $9 \mathrm{a} . \mathrm{m}$. They were all assessed preoperatively in the ward by the same anaesthetist who also gave all the anaesthetics in a standard fashion. Surgery was performed by the allotted surgeon using the same technique, instrumentation and suture materials.

In the 'conventional' group oxyphenbutazone/ chloramphenicol ointment was applied to the eye at the end of surgery and twice daily for 14 days there-

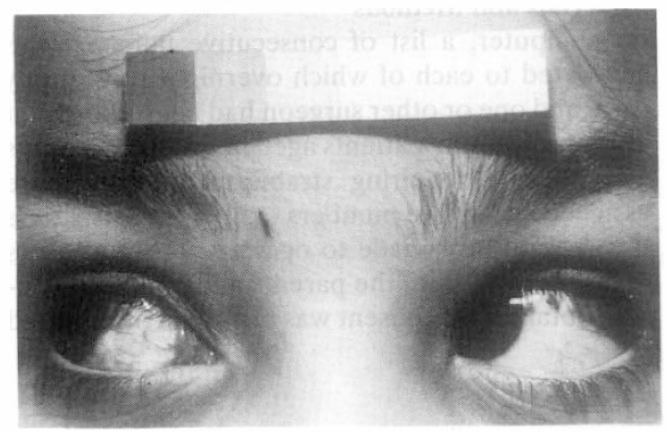

Fig. 2. Photograph of eyes 21 days after operation with grading scale in place.

after. Patients were allowed home after midday on the day following surgery.

In the 'study' group patients were allowed home in the evening after surgery so long as recovery was uneventful.

\section{Post-operative Assessment}

Patients were seen at 24 hours, 72 hours, 7 days and 21 days post-operatively. The same parent was asked to accompany the child each time and to answer a questionnaire (Fig. 1).

Post-operative inflammation was assessed simply by recording the redness of the eyes. This was graded by comparison with a standard scale with 5 intervals between white and blood red (grades 1-6). The standard scale was fixed to the patient's forehead. Photographs were taken at each visit (Fig. 2).

The presence of discharge or watering was noted and any miscellaneous observations recorded. Axillary temperature was measured.

\section{Results}

Of the 42 patients, one surgeon operated on 23 (11 overnight and 12 days cases) and the other on 19 (11 overnight and 8 day cases).

No medical complications occurred in any patient.

Parental compliance was excellent but in each group 2 patients did not attend for the 3 week assessment.

\section{Parental Questionnaire}

Vomiting occurred in the first 24 hours after surgery in 50 per cent of the overnight cases and 25 per cent of the day cases (not statistically significant). This was mostly at night. In the overnight cases this was not related to whether or not the mother stayed in hospital with the child. Three of the overnight stay and 7 of the day cases were thought by the parents to be pyrexial in the first 24 hours. In fact only one raised temperature was recorded in the whole study and this was in an overnight stay patient at 24 hours.

Apparent discomfort was more frequently reported in the 'conventional' group (Table I).

\section{Post-operative Inflammation}

In both groups early watering and discharge were minimal.

There was no statistical difference between 
Table I. Discomfort judged from eye rubbing

\begin{tabular}{|c|c|c|c|c|c|}
\hline & & $\begin{array}{c}24 \\
\text { hours }\end{array}$ & $\begin{array}{c}72 \\
\text { hours }\end{array}$ & 1 week & 3 weeks \\
\hline $\mathrm{O} / \mathrm{N}$ & slight & 11 & 6 & 9 & 2 \\
\hline$(22)$ & moderate & 0 & 3 & 0 & 0 \\
\hline DAY & slight & 7 & 1 & 1 & 0 \\
\hline (20) & moderate & 1 & 0 & 0 & 0 \\
\hline
\end{tabular}

Table II. Eye redness scores

\begin{tabular}{|c|c|c|c|c|c|}
\hline grade & & $\begin{array}{c}24 \\
\text { hours }\end{array}$ & $\begin{array}{c}72 \\
\text { hours }\end{array}$ & 1 week & 3 weeks \\
\hline \multirow[t]{2}{*}{6} & $\mathrm{O} / \mathrm{N}$ & 15 & 12 & 0 & 0 \\
\hline & DAY & 13 & 10 & 1 & 0 \\
\hline \multirow[t]{2}{*}{5} & $\mathrm{O} / \mathrm{N}$ & 6 & 10 & 6 & 0 \\
\hline & DAY & 6 & 10 & 7 & 1 \\
\hline \multirow[t]{2}{*}{4} & $\mathrm{O} / \mathrm{N}$ & 1 & 0 & 10 & 2 \\
\hline & DAY & 1 & 0 & 7 & 3 \\
\hline \multirow[t]{2}{*}{3} & $\mathrm{O} / \mathrm{N}$ & 0 & 0 & 6 & 8 \\
\hline & DAY & 0 & 0 & 4 & 5 \\
\hline \multirow[t]{2}{*}{2} & $\mathrm{O} / \mathrm{N}$ & 0 & 0 & 0 & 8 \\
\hline & DAY & 0 & 0 & 0 & 5 \\
\hline \multirow[t]{3}{*}{1} & $\mathrm{O} / \mathrm{N}$ & 0 & 0 & 0 & 2 \\
\hline & DAY & 0 & 0 & 1 & 4 \\
\hline & Total & 42 & 42 & 42 & 38 \\
\hline
\end{tabular}

the mean redness scores of the eye in the 2 groups at any time point ( $\mathrm{t}$ test: 95 per cent confidence interval at 1 week $-0.69-+0.49$ and at 3 weeks $-0.73-+0.62$ ). (Table II and Fig. 3).

\section{Failures}

Four families expressed unwillingness to participate in any type of study and a fifth refused

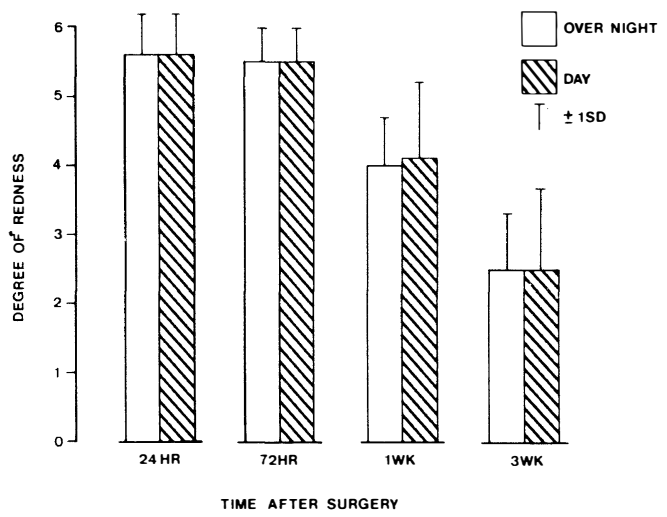

Fig. 3. Mean post-operative redness score. consent because they would have had great difficulty attending the follow-up programme. One patient was referred elsewhere for a second opinion, one was removed from the study after a cardiac murmur was noted, and another left the area after surgery and was followed up elsewhere.

\section{Discussion}

In this study discharge from hospital on the day of surgery without medication was not found to be detrimental to the patients. Routine use of ocular medication carries the risk of allergic reactions, systemic side effects and distress to the child and parents. The mothers of 6 of the 'conventional' group patients made unsolicited comments about the difficulty of administering the ointment, and how much their children appeared to resent it. Several admitted that because of this application had been irregular. Consequently we suspect that compliance in giving eye medication to children is, in general, poor.

As shown in Table I, children in the "conventional' group appeared to rub their eyes more. This is a very subjective assessment but it is possible that some soreness could be caused by the ointment. Persistent rubbing might lead to increased inflammation and delayed healing.

Anxiety as a result of being in unfamiliar surroundings might account for the apparent increased vomiting in the children kept in hospital overnight.

Although parental responses are very subjective, we do feel that the management of the 'study' group was socially advantageous. The financial benefits to the health care system are obvious.

\section{Conclusion}

We suggest that day case surgery for strabismus is safe and routine post-operative medication unnecessary so long as adequate time for recovery from anaesthesia is allowed, and an open access system provided through which parents are encouraged to report their concerns immediately to the team responsible for their child's care. The close surveillance 
performed in this study in the first post-operative week does not appear to be necessary.

We are most grateful to Dr. John Dawson, Consultant Anaesthetist, the Ashford Hospital, for his advice and support in this study, to Mr. Peter Clark of the Institute of Ophthalmology for providing the random list, to Mr. Alan Perkins, North West Thames Regional Information Manager for his help with the statistics, and to Miss Jill Pearce and Mr. Clive Oakley, medical photographers, the West Middlesex University Hospital, for taking the photographs. The study was supported by a grant from the West Middlesex University Hospital Research Fund.

\section{References}

${ }^{1}$ Hadaway EG, Ingram RM, Traynar MJ: Day case surgery for strabismus in children. Trans Ophthalmol Soc UK 1977, 97: 23-5.

${ }^{2}$ Guidelines for day case surgery. Commission on the provision of surgical services. Royal College of Surgeons of England. London, 1985: 18. 